\title{
SUPPLEMENTARY ONLINE DISCUSSION
}

Epicontinental-Sea versus Open-Ocean Settings: A Fundamental Phanerozoic Marine Dichotomy

As noted in the main text, at the heart of this investigation is the use and recognition of epicontinental seas versus open-ocean-facing settings as a fundamental dichotomy among Phanerozoic marine settings. The rationale for this dichotomy is discussed by Miller and Foote (2009), and a fuller description of the basis and method for assigning occurrences of Permian through Cretaceous genera to the two settings is provided in the online supplement for that paper, available at:

http://www.sciencemag.org/content/suppl/2009/11/18/326.5956.1106.DC1/Miller.SOM.pdf

In the context of the present study, it is reasonable to ask whether dividing the marine world with respect to any dichotomy is an oversimplification, destined to be conflated with more meaningful environmental variables that governed the environmental distributions of marine organisms. In the case of epicontinental seas versus open-ocean-facing settings, there are two environmental variables in particular that one might suspect as being the "true" arbiters of the observed biotic distributions. The first is sedimentological; all else being equal, we might expect epicontinental seas to be more closely associated with carbonate sedimentation and ocean-facing settings to be more closely associated with siliciclastic sedimentation (e.g., Walker et al. 2002, Peters 2008). The second is climatological; in general, epicontinental seas were more closely associated with tropical, low latitude settings, whereas ocean-facing settings likely covered a broader latitudinal ranges, but with considerable representation outside of the tropics. However, as Miller and Foote (2009) documented in their analysis of origination and extinction rates in the two settings for the Permian through Cretaceous, the fundamental patterns recognized in their investigation were conserved even when restricting their analyses to subsets of the data extracted only from carbonate, low-latitude occurrences or from siliciclastic, high-latitude occurrences. It therefore appears that environmental conditions directly associated with epicontinental seas versus open-ocean-facing settings were at play. Given the geometry of epicontinental seas-areal coverages ranging from thousands to hundreds of thousands of square kilometers, with water depths of no more than several tens to perhaps a couple of hundred meters-it stands to reason that circulation would, on average, be significantly more sluggish than in comparably sized areas of the open ocean. As summarized by Allison and Wells (2006), this sluggishness was manifested in several ways, including: a) depressed tidal ranges, with computer models (e.g., Slingerland 1986, Wells et al. 2005a, 2005b) suggesting that epicontinental seas were microtidal; b) regionalization of water-masses with significant geographic variation over relatively small distances in geochemical properties such as $\delta^{13} \mathrm{C}$ (Panchuk et al. 2006); c) a decided lack of turbulence during tidal exchange, in contrast to shallow areas of the open ocean marked by greater tidal ranges; and d) enhanced stratification of water masses, even though water depths were fairly shallow, with increased possibilities of anoxic or hypoxic episodes (Peters 2007). 
Recent modeling (Mitchell et al. 2010) has also suggested that tsunamis and other disturbances would propagate far more easily in open-ocean settings than in epicontinental seas.

Allison, P.A., and Wells, M.R., 2006, Circulation in large ancient epicontinental seas: What was different and why?: Palaios, v. 21, p. 513-515.

Mitchell, A.J., Allison, P.A., Piggott, M.D., Gorman, G.J., Pain, C.C., and Hampson, G.J. 2010. Numerical modeling of tsunami propogation with implications for sedimentation in ancient epicontinental seas: The Lower Jurassic Laurasian seaway. Sedimentary Geology, v. 228, p. 81-97.

Panchuk, K. M., Holmden, C.E., and Leslie, S.A.. 2006. Local controls on carbon cycling in the Ordovician midcontinent region of North America, with implications for carbon isotope secular curves. Journal of Sedimentary Research, v.76, 200-211.

Peters, S.E., 2007, The problem with the Paleozoic: Paleobiology, v. 33, p. 165-181.

Peters, S.E., 2008, Environmental determinants of extinction selectivity in the fossil record: Nature, v. 454, p. 626-629.

Slingerland, R. 1986. Numerical computation of co-oscillating paleotides in the Catskill epeiric sea of eastern North-America. Sedimentology, v. 33, 487-497.

Walker, L. J., B. H. Wilkinson, and L. C. Ivany. 2002. Continental drift and Phanerozoic carbonate accumulation in shallow-shelf and deep-marine settings. Journal of Geology, v. 110, p. $75-87$.

Wells, M. R., P. A. Allison, G. J. Hampson, M. D. Piggott, and C. C. Pain. 2005a. Modelling ancient tides: the Upper Carboniferous epi-continental seaway of Northwest Europe. Sedimentology, v. 52, 715-735.

Wells, M. R., P. A. Allison, M. D. Piggott, C. C. Pain, G. J. Hampson, and C. R. E. De Oliveira. 2005b. Large sea, small tides: the Late Carboniferous seaway of NW Europe. Journal of the Geological Society, v. 162, 417-420. 


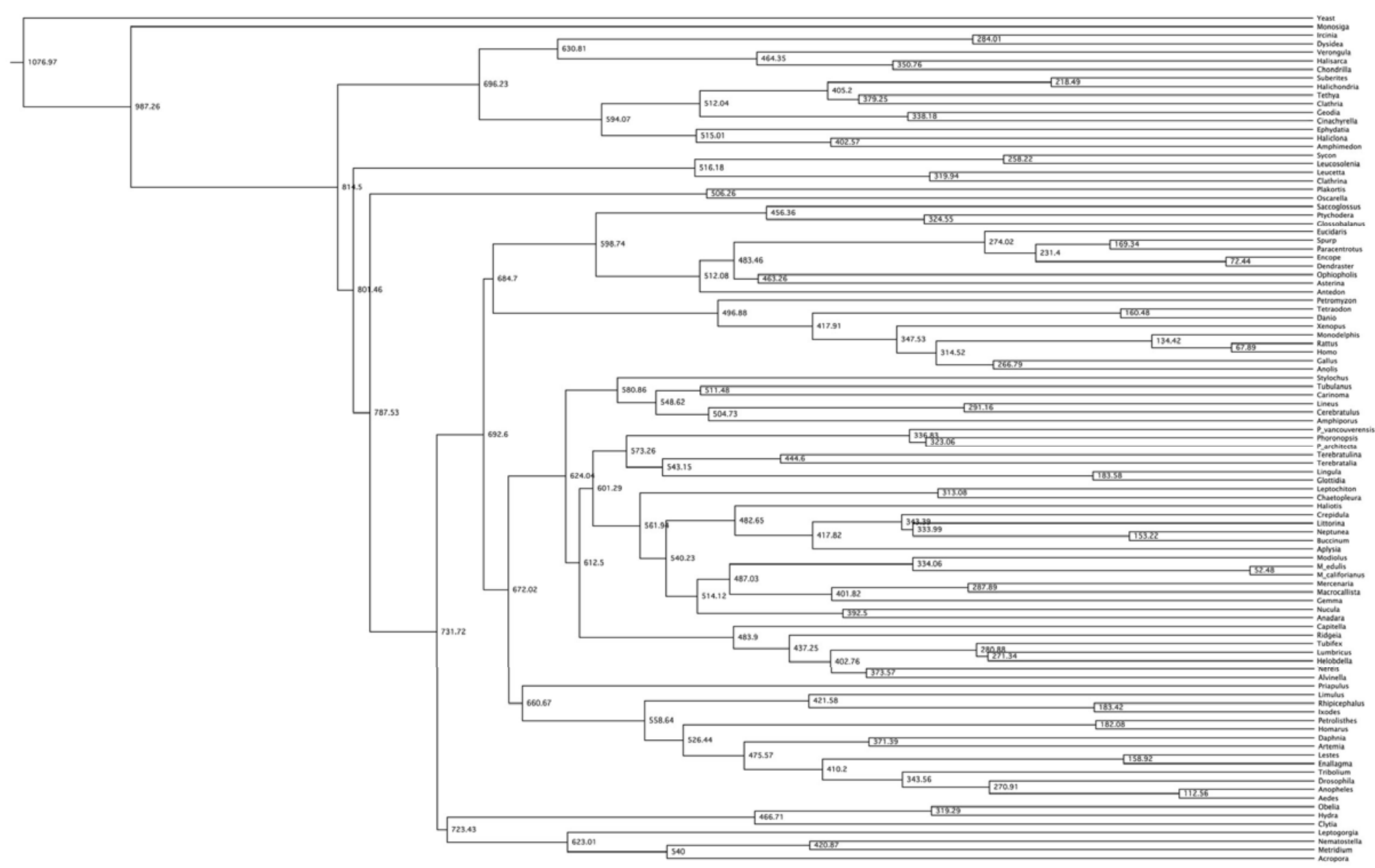




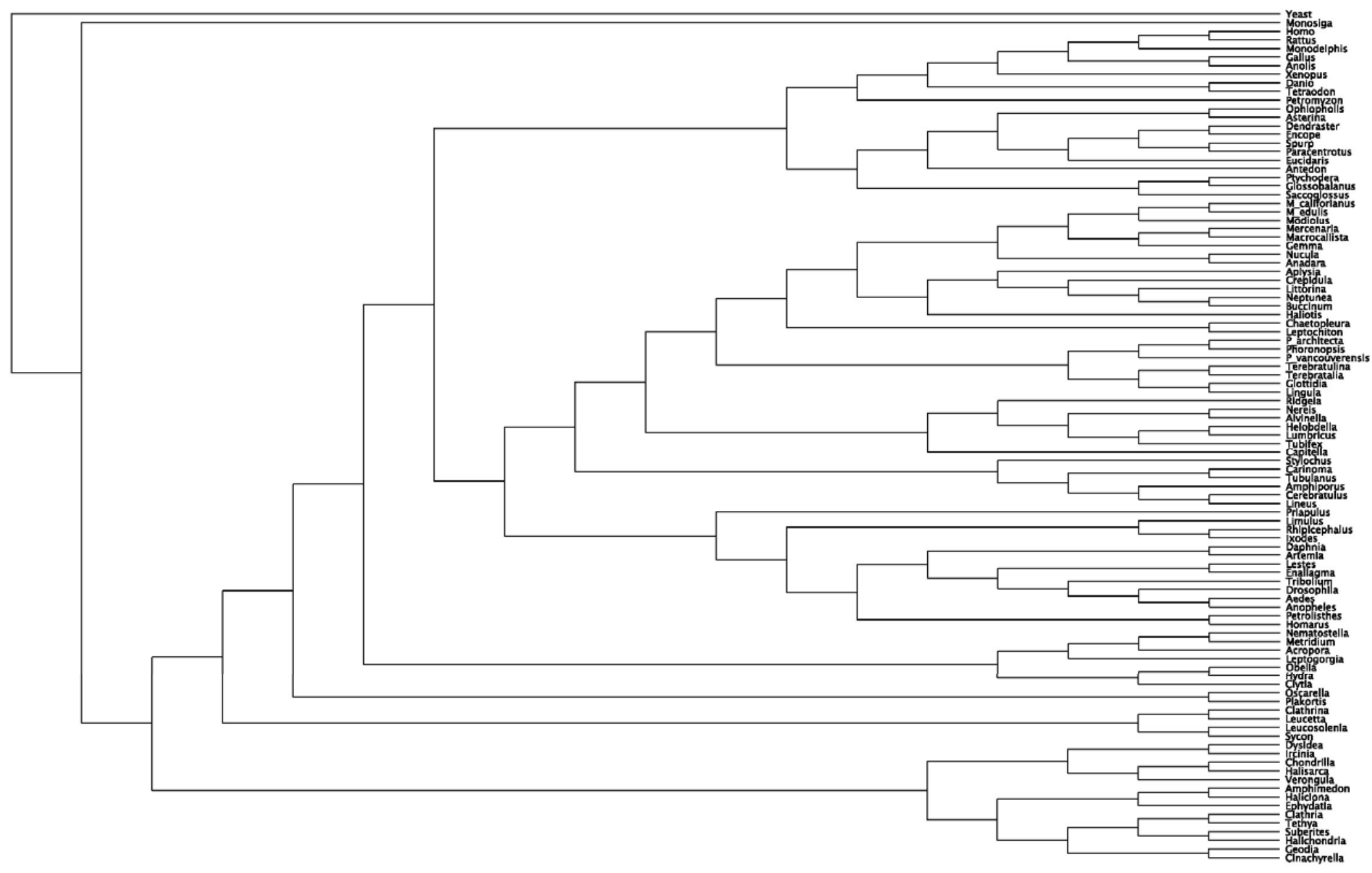

0.0 